Erratum

\title{
Erratum to "The Role of a Selective P2Y 6 Receptor Antagonist, MRS2578, on the Formation of Angiotensin II-Induced Abdominal Aortic Aneurysms"
}

\author{
Xiao Du, ${ }^{1}$ Shilan Zhang, ${ }^{2}$ Qunyan Xiang, ${ }^{1}$ Jingyuan Chen, ${ }^{1}$ Feng Tian, ${ }^{1}$ Jin Xu, ${ }^{1}$ Xin Li, \\ Yuansheng Tan, ${ }^{3}$ and Ling Liu (1) ${ }^{1}$ \\ ${ }^{1}$ Department of Cardiovascular Medicine, The Second Xiangya Hospital, Central South University, Changsha, Hunan 410011, China \\ ${ }^{2}$ Department of Gastroenterology, The Second Xiangya Hospital, Central South University, Changsha, Hunan 410011, China \\ ${ }^{3}$ Ministry of Education, Hospital of Hunan University of Traditional Chinese Medicine, Changsha, Hunan 410011, China \\ Correspondence should be addressed to Ling Liu; feliuling@csu.edu.cn \\ Received 20 September 2020; Accepted 20 September 2020; Published 30 September 2020 \\ Copyright (C) 2020 Xiao Du et al. This is an open access article distributed under the Creative Commons Attribution License, which \\ permits unrestricted use, distribution, and reproduction in any medium, provided the original work is properly cited.
}

In the article titled "The Role of a Selective $\mathrm{P}_{2} \mathrm{Y}_{6}$ Receptor Antagonist, MRS2578, on the Formation of Angiotensin II-Induced Abdominal Aortic Aneurysms" [1], there was an error in affiliation numbers 1 and 2 . The address line of "The Second Xiangya Hospital" was missing in both affiliations. This error was introduced during the production of the article, and the publisher apologises for this error. The corrected affiliations appear in the affiliation list.

\section{References}

[1] X. Du, S. Zhang, Q. Xiang et al., “The role of a selective $\mathrm{P}_{2} \mathrm{Y}_{6}$ Receptor antagonist, MRS2578, on the formation of angiotensin II-induced abdominal aortic aneurysms," BioMed Research International, vol. 2020, Article ID 1983940, 15 pages, 2020. 